\title{
Produção científica e impacto em Saúde Coletiva
}

Ao longo das últimas décadas, foram notórias a expansão e a consolidação da pós-graduação em Saúde Coletiva no país. Tal expansão foi seguida do surgimento de novos grupos e linhas de pesquisa, muitos dos quais voltados para o equacionamento dos muitos desafios impostos pela saúde pública no âmbito regional. Sabe-se que, a depender de um conjunto de fatores (tema da pesquisa, abordagens metodológicas, inserção institucional do grupo de pesquisa), um determinado pesquisador poderá ter menor ou maior facilidade para publicação de seus trabalhos em revistas internacionais de maior prestígio. Em face ao tênue equilíbrio entre interesse "global" e interesse "regional" em ciência, torna-se premente o aprofundamento da discussão sobre a avaliação da produção científica na grande área da saúde e, em especial, na Saúde Coletiva. Afinal, quem define nossas agendas de pesquisa?

Um estudo recente publicado no Canadian Medical Association Journal por Rochon e colaboradores (v. 170, p. 1673, 2004) analisou artigos publicados em seis conceituadas revistas. Além do próprio CMAJ, foram incluídos os periódicos Ann Intern Med, BMJ, JAMA, Lancet e $N$ Engl J Med. A escolha desses periódicos deu-se a partir do reconhecimento da influência que publicações desse porte podem exercer na determinação de agendas de pesquisa internacionais e, por conseguinte, de linhas de financiamento, dentre outras prioridades. Especificamente, o estudo analisou a relação entre a "carga global de doença” e doenças pesquisadas em um total de 286 ensaios controlados. Os autores concluíram que muitas doenças de importância na determinação da "carga global" nos países em desenvolvimento estão sub-representadas. Apenas 1/3 dos estudos sobre HIV/AIDS foi realizado em países fora do eixo América do Norte-Europa Ocidental. Importantes endemias de forte presença no perfil de morbi-mortalidade em inúmeros países, foram objeto de pouquíssimas investigações.

O estudo canadense não emerge como um caso isolado. Soma-se à literatura crítica que, reiteradamente, aponta para um distanciamento entre as agendas que predominam na assim chamada "ciência de ponta" e as demandas do dia-a-dia da saúde pública mundial, em especial no que diz respeito aos países do terceiro mundo. Tal orientação faz-se refletir nas políticas editoriais que prevalecem nas grandes revistas produzidas no mundo anglo-saxão. Nesse contexto, as revistas editadas nos países em desenvolvimento assumem uma posição estratégica na veiculação da produção científica gerada nessa região, em concatenação com as linhas e prioridades de pesquisa ali estabelecidas. Países como o Brasil exercem grande influência nesse processo, não só por sua expressiva produção científica, mas também por ser responsável pelo maior número de revistas na área da saúde editadas na América Latina.

É importante que as agências, universidades e institutos de pesquisa brasileiros que têm implementado mecanismos de avaliação da produção científica apóiem as revistas nacionais. Nesse campo, todo cuidado é pouco. Como tive a oportunidade de destacar recentemente, com o objetivo de qualificar as revistas científicas e, por extensão, os artigos nelas publicados, tem sido adotado e rapidamente disseminado no Brasil um indicador bibliométrico até pouco tempo atrás pouquíssimo conhecido no país - o fator de impacto. Mesmo que esse fator seja sensível para avaliar revistas em determinadas áreas do conhecimento, pairam muitas dúvidas acerca de sua propriedade à saúde coletiva. Trata-se de uma discussão densa, mas é questionável que a qualidade da produção editorial nessa área possa ser aferida por meio de um parâmetro tão simplificado.

A publicação científica é parte intrínseca do processo de produção do conhecimento científico e da inovação. O fortalecimento das revistas científicas nacionais é uma condição sine qua non para o contínuo avanço da base de ciência e tecnologia no Brasil. É imprescindível não somente a alocação de recursos, como também de exercícios criativos de como proceder a avaliação da produção científica, indo além da absorção e replicação de critérios que, como já bem estabelecido, não são generalizáveis para todas as áreas do conhecimento.

Carlos E. A. Coimbra Jr.

Editor 